LA-UR- $98-3669$

Approved for publlc release; distribution is unlimited.

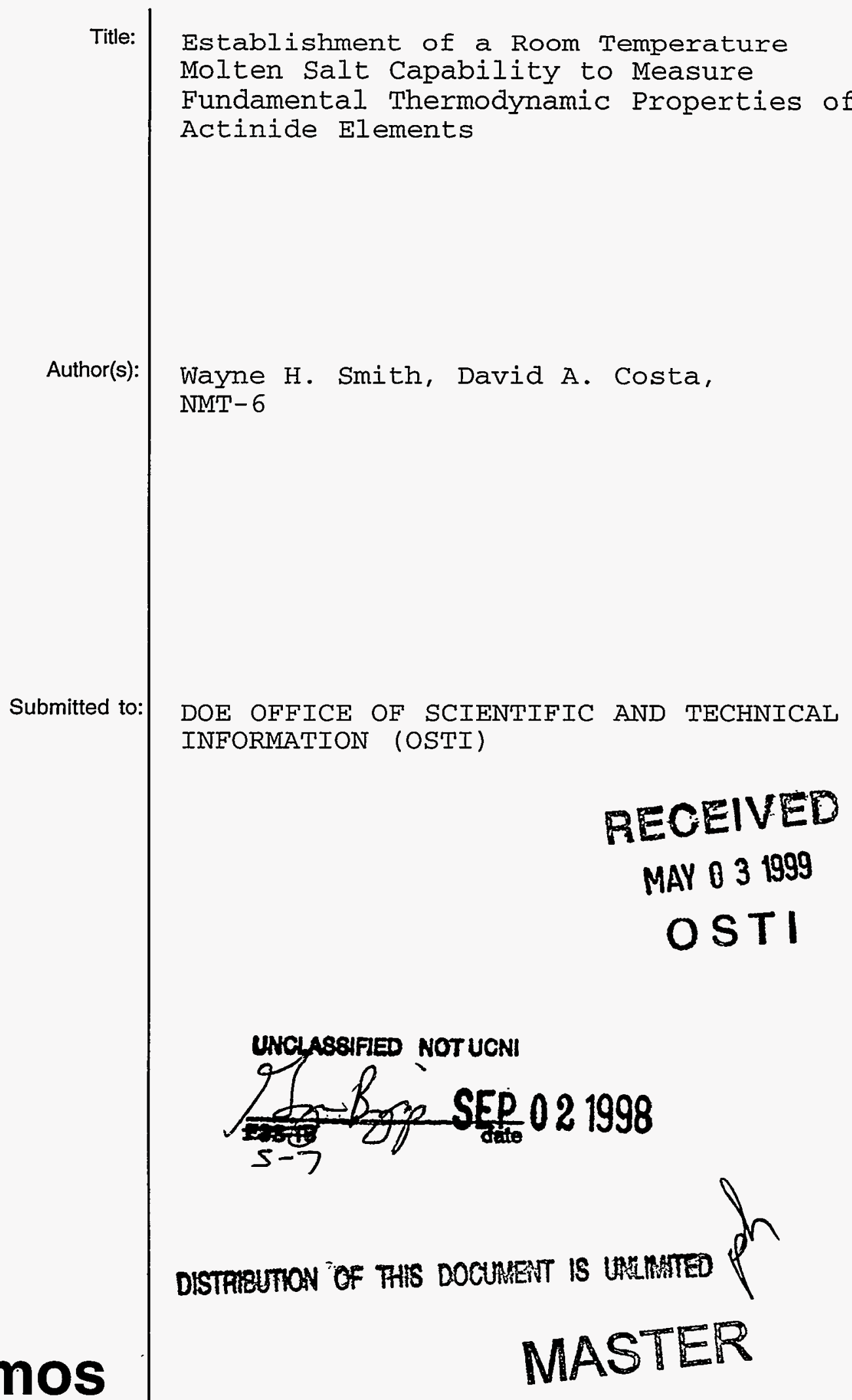

Los Alamos National Laboratory, an affirmative action/equal opportunity employer, is operated by the University of California for the U.S. Department of Energy under contract W-7405-ENG-36. By acceptance of this article, the publisher recognizes that the U.S.

Government retains a nonexclusive, royalty-free license to publish or reproduce the published form of this contribution, or to allow others to do so, for U.S. Government purposes. Los Alamos National Laboratory requests that the publisher identify this article as work performed under the auspices of the U.S. Department of Energy. The Los Alamos National Laboratory strongly supports academic freedom and a researcher's right to publish; as an institution, however, the Laboratory does not endorse the viewpoint of a publication or guarantee its technical correctness. 


\section{DISCLAIMIER}

This report was prepared as an account of work sponsored by an agency of the United States Governmear. Neither the United States Governmeat aor any agency thereof, nor any of their employees, makes any waranty, express or implied. or essumes any legal liability or responsibility for the aceuracy, completeness, or usefulness of any information, apparatus, produer, or process dicelosed. or represents that its use would not infringe privately owned rights. Refereace berein to any specific commercial product, process, or service by trade name, ezadernart, inanufac. turet, or otherwise does not atecessarily constitute or imply its endorsement. recommendation, or favoring by the United States Governmeat or any agency thereof. The views and opinions of authors expressed herein do not necsesaily seate or rellect those of the United States Goverameat or any agency thereof. 


\section{DISCLAIMER}

Portions of this document may be illegible in electronic image products. Images are produced from the best available original document. 


\title{
Establishment of a Room Temperature Molten Salt Capability to Measure Fundamental Thermodynamic Properties of Actinide Elements
}

\author{
Wayne H. Smith* and David A. Costa
}

\begin{abstract}
This is the final report of a six-month, Laboratory Directed Research and Development (LDRD) project at Los Alamos National Laboratory (LANL). The goal of this work was to establish a capability for the measurement of fundamental thermodynamic properties of actinide elements in room temperature molten salts. This capability will be used to study in detail the actinide chloro- and oxo- coordination chemistries that dominate in the chloride-based molten salt media. Uranium will be the first actinide element under investigation.
\end{abstract}

\section{Background and Research Objectives}

Many of the actinide element recovery and purification processes are currently conducted in high temperature molten salt systems, with operating temperatures at greater than $700^{\circ} \mathrm{C}$. The high operating temperatures and corrosive nature of these chloride-based salts greatly inhibit the ability to study the chemical reactions taking place in these media. Yet a knowledge of this chemistry is essential to optimizing the efficiencies of these processes. The room temperature salts used in this study are similarly chloride based but because they are used at room temperature are far less corrosive and much more amenable to standard characterization techniques. The room temperature molten salts (RTMS) we are dealing with are composed of aluminum trichloride and an organic chloride salt. These mixtures are characterized by a melting point at or near room temperature, a very wide potential window of approximately 5 volts, and an equally wide spectroscopic window that extends from the ultraviolet to the infrared spectral regions. They also exhibit the unique ability of having their acidity/basicity adjusted over a wide range by varying the ratio of the two solvent constituents. These properties allow for accurate characterization of dissolved species using electrochemical and spectroscopic methods.

Over the past several years a number of researchers have investigated the redox properties and spectral characteristics of most of the naturally occurring metallic elements. However, of the actinide elements, only neptunium ${ }^{1}$ and uranium ${ }^{2 \cdot 6}$ have been studied in

*Principal Investigator, e-mail address: wsmith@lanl.gov 
these solvent systems, with the latter element receiving the most attention. Our goal for this project is to establish a RTMS capability and to complete the characterization of uranium in this medium. Of specific interest is the synthesis and characterization of mono- and dioxocomplexes of uranium in high oxidation states, which are the species expected to exist in the high temperature salts. This characterization will include the measure of the formation constants for the complexes as well as the determination of the kinetics of ligand exchange on reduction to lower oxidation states.

The information resulting from this study will serve as a benchmark for future characterization of other actinide elements, and ultimately to predict the chemical behavior of actinide elements in the high-temperature chloride-based salts currently used in actinide recovery and purification processes.

\section{Importance to LANL's Science and Technology Base and National R\&D Needs}

The Laboratory maintains core competencies in areas that include the determination of the physical and chemical properties of actinide elements. These core competencies are aimed at obtaining a better understanding of the fundamental properties of these elements, leading to the development of new actinide purification and recovery processes and to the treatment of waste and environmental remediation, all within the scope of DOE missions.

\section{Scientific Approach and Accomplishments}

A total characterization of the chemical behavior of uranium in RTMS systems can be divided into four distinct sub-studies that depend on the initial chemical oxidation state of uranium added to the melt, and to the acidity/ basicity of the melt itself. Both uranyl, $\mathrm{UO}_{2}{ }^{2+}$, and $\mathrm{U}^{4+}$ are stable in the basic melts; $\mathrm{U}^{4+}$ is also stable in acidic melts. Previous studies have characterized these three systems. Conspicuously absent, but necessary to complete the study on the chemical behavior of uranium in RTMS, is a study of $\mathrm{UO}_{2}^{2+}$ in an acidic melt. Our initial goal then is to set up the RTMS capability and complete the uranium characterization. Soon after initiating this project we learned that Professor Greg Choppin at Florida State University was involved in a similar study, which led to a collaboration between the two laboratories.

Our first observation was that uranyl was unstable in acidic melts, ultimately giving rise to a non-oxygenated uranium +5 species according to reaction (1). The overall reaction

$$
\mathrm{UO}_{2}^{2+}+\mathrm{e}-\rightarrow \mathrm{U}^{5+}+2 \mathrm{O}^{2-}
$$


involved the uptake of one electron and the loss of two oxygen anions. Combined spectroscopic and electrochemical methods were used to establish the kinetics and mechanism of this reaction.

Spectroscopic studies showed that the reaction took place in two steps. In the first step, which took place over a period of a few hours, the original uranyl species reacted to produce a long-lived intermediate. This intermediate species then reacted more slowly over a period of several days to produce the final uranium +5 product.

The electrochemical behavior of uranyl in the acidic melt is shown in the cyclic voltammogram in Figure 1. Each of the waves in the voltammogram indicates an electron transfer process. The wave assignments are based on previously published results and chemical inference. A summary of these assignments is presented in graphical form in Figure 2. Since no chemical reducing agents were added to the solution, the reduction of uranyl to uranium +5 must be due to reaction with the solvent. The two dominant components of the melt are $\mathrm{AlCl}_{4}{ }^{-}$and $\mathrm{Al}_{2} \mathrm{Cl}_{7}{ }^{-}$, either of which may be oxidized to form $\mathrm{Cl}_{2}$. The redox potential for this process is given by the anodic solvent limit that occurs at approximately 2.7 volts. This process has been added to Figure 2 for reference and in support of the following discussion.

The relative positioning of lines in Figure 2 is a measure of the thermodynamic driving force for electron transfer reactions and is indicative of the relative reactivity of the species represented on either side of the line. Species separated by two lines react spontaneously and the greater the distance between the two lines, the greater the tendency for the species to react. For example, $\mathrm{UO}^{4+}$ will react spontaneously with $\mathrm{UO}_{2}{ }^{1+}$ to produce $\mathrm{UO}^{3+}$ and $\mathrm{UO}_{2}^{2+}$. Similarly, $\mathrm{U}^{6+}$ will react spontaneously with $\mathrm{UO}^{3+}$ to produce $\mathrm{U}^{5+}$ and $\mathrm{UO}^{4+}$.

From this graph it can be seen that none of the possible uranium +6 species, dioxo, mono-oxo or non-oxo, will enter into a spontaneous electron transfer reaction with the solvent. However, since each of the redox reactions represents a dynamic equilibrium, the reactions can occur to a limited extent. Once again the distance between the lines on the graph is indicative of the extent of the reaction. In this case the reaction between $\mathrm{U}^{6+}$ and $\mathrm{AlCl}_{4}{ }^{-}$to produce $\mathrm{U}^{5+}$ and $\mathrm{Cl}_{2}$ is unfavorable. The reaction between $\mathrm{UO}^{4+}$ and $\mathrm{AlCl}_{4}{ }^{-}$to produce $\mathrm{UO}^{3+}$ and $\mathrm{Cl}_{2}$ is more unfavorable and between $\mathrm{UO}_{2}{ }^{2+}$ and $\mathrm{AlCl}_{4}^{-}$to produce $\mathrm{UO}_{2}{ }^{1+}$ and $\mathrm{Cl}_{2}$ is most unfavorable. The relative order of reactivity between the solvent and uranium +6 species is therefore $\mathrm{U}^{6+}>\mathrm{UO}^{4+}>\mathrm{UO}_{2}{ }^{2+}$.

In addition to the electron transfer reaction, there is an acid-base-type reaction that is known to occur in the melts. In this case a basic species, $\mathrm{UO}_{2}^{2+}$, can react with the acidic melt component, $\mathrm{Al}_{2} \mathrm{Cl}_{7}^{-}$according to equation (2). 


$$
\mathrm{UO}_{2}^{2+}+\mathrm{Al}_{2} \mathrm{Cl}_{7}^{-} \leftrightarrow \mathrm{UO}^{4+}+\mathrm{AlCl}_{4}^{-}+\mathrm{AlOCl}_{3}^{2-}
$$

The second oxygen can be removed in a similar reaction as shown in equation (3).

$$
\mathrm{UO}^{4+}+\mathrm{Al}_{2} \mathrm{Cl}_{7}^{-} \leftrightarrow \mathrm{U}^{6+}+\mathrm{AlCl}_{4}^{-}+\mathrm{AlOCl}_{3}^{2-}
$$

An overall reaction matrix showing all possible species that can exist between the starting uranyl ion, $\mathrm{UO}_{2}^{2+}$, and the final uranium +5 , non-oxo product is presented in Figure 3 .

Based on electrochemical and spectroscopic measurements, the most likely reaction mechanism calls for a relatively rapid acid-base reaction between the acidic solvent and basic uranyl ion followed by a very slow electron transfer reaction between the $\mathrm{U}^{6+}$ intermediate and the solvent. Uranium +6 in an acidic melt distributes itself between the dioxo, mono-oxo and non-oxo species, similar to how a diprotic acid distributes itself between di-, mono- and non-protonated species in aqueous solution. Of the three uranium +6 species present at equilibrium, the least unfavorable reduction reaction involving the non-oxo species is the one that is rate determining. Thus the overall reaction can be represented by equation (4).

$$
\mathrm{UO}_{2}^{2+} \leftrightarrow \rightarrow \mathrm{UO}^{4+} \leftrightarrow \rightarrow \mathrm{U}^{6+} \rightarrow \mathrm{U}^{5+}
$$

Future work on this topic will involve a search for the mono-oxo uranium +6 species, $\mathrm{UO}^{4+}$. This species is unstable in all other solvent media and as a result has not been characterized. However, it may be possible to stabilize this species in the RTMS by decreasing the acidity of the melt and by further shifting the acid-base equilibrium toward the intermediate with addition of oxide dianion, $\mathrm{O}^{2-}$. With the uranium system then fully characterized, work in this area would focus on the chemical behavior of other actinide elements in RTMS systems, beginning with plutonium and neptunium.

\section{Publications}

1. Anderson C. J., Choppin G. R., Pruett D. J., Costa D. A. and Smith W. H., "Electrochemistry and Spectroscopy of $\mathrm{UO}_{2}^{2+}$ in Acidic $\mathrm{AlCl}_{3}$-EMIC," Radiochimica Acta, submitted for publication.

\section{Presentations}

1. Smith W. H., Costa D. A. and DeRege F., "Determination of Thermodynamic Properties of Actinide Elements in Room Temperature Molten Salts," Plutonium Futures '97, Santa Fe, NM, August 1997.

2. Costa D. A. and Smith W. H., "The Redox behavior of Uranyl Chloride.in Acidic RTMS," $193^{\text {rd }}$ Meeting of the Electrochemical Society, San Diego, CA, May, 1998. 


\section{References}

[1] Schoebrechts J. P., and Gilbert B., "Electrochemical and Spectroscopic Studies of Neptunium in the Aluminum Chloride-1-n-Butlypyridinium Chloride Melt at $40^{\circ} \mathrm{C}$," Inorg. Chem. 24, 2105-2110, (1985).

[2] De Waele R., Heerman L., and D'Olieslager W., "Electrochemistry of Uranium(IV) in Acidic $\mathrm{AlCl}_{3}+\mathrm{N}$-(n-Butyl)Pyridinium Chloride Room-Temperature Molten Salts," J. Electroanal. Chem. 142, 137-146, (1982).

[3] De Waele R., Heerman L., and D'Olieslager W., "Potentiometric and Spectroscopic Study of Uranium(IV)/Uranium(III) in Acidic $\mathrm{AlCl}_{3}-\mathrm{N}$-(n-Butyl)Pyridinium Chloride Melts," J. Less Common Metals 122, 319-327, (1986).

[4] Hitchcock P. B., Mohammed T. J., Seddon K. R., Zora J. A., Hussey C. L., and Ward E. H., "1-Methyl-3-ethyl imidazolium Hexachlorouranate(IV) and 1-Methyl-3ethylimidazolium Tetrachlorodioxouranate(VI): Synthesis, Structure, and Electrochemistry in a Room Temperature Ionic Liquid," Inorg. Chim. Acta 113, L25-L26, (1986).

[5] De Waele R., Heerman L., and D'Olieslager W., "Electrochemistry and Spectroscopy of Uranium in Basic $\mathrm{AlCl} 3+\mathrm{N}$-(n-Butyl)Pyridinium Chloride Room-Temperature Molten Salts," J. Electroanal. Chem. 193, 289-294, (1985).

[6] Anderson C. J., Deakin M. R., Choppin G. R., D'Olieslager W., Heerman L., and Pruett D. J.." "Spectroscopy and Electrochemistry of U(IV)/U(m) in Basic Aluminum Chloride-1-Ethyl-3-methylinidazolium Chloride," Inorg. Chem. 30, 4013-4016, (1991). 


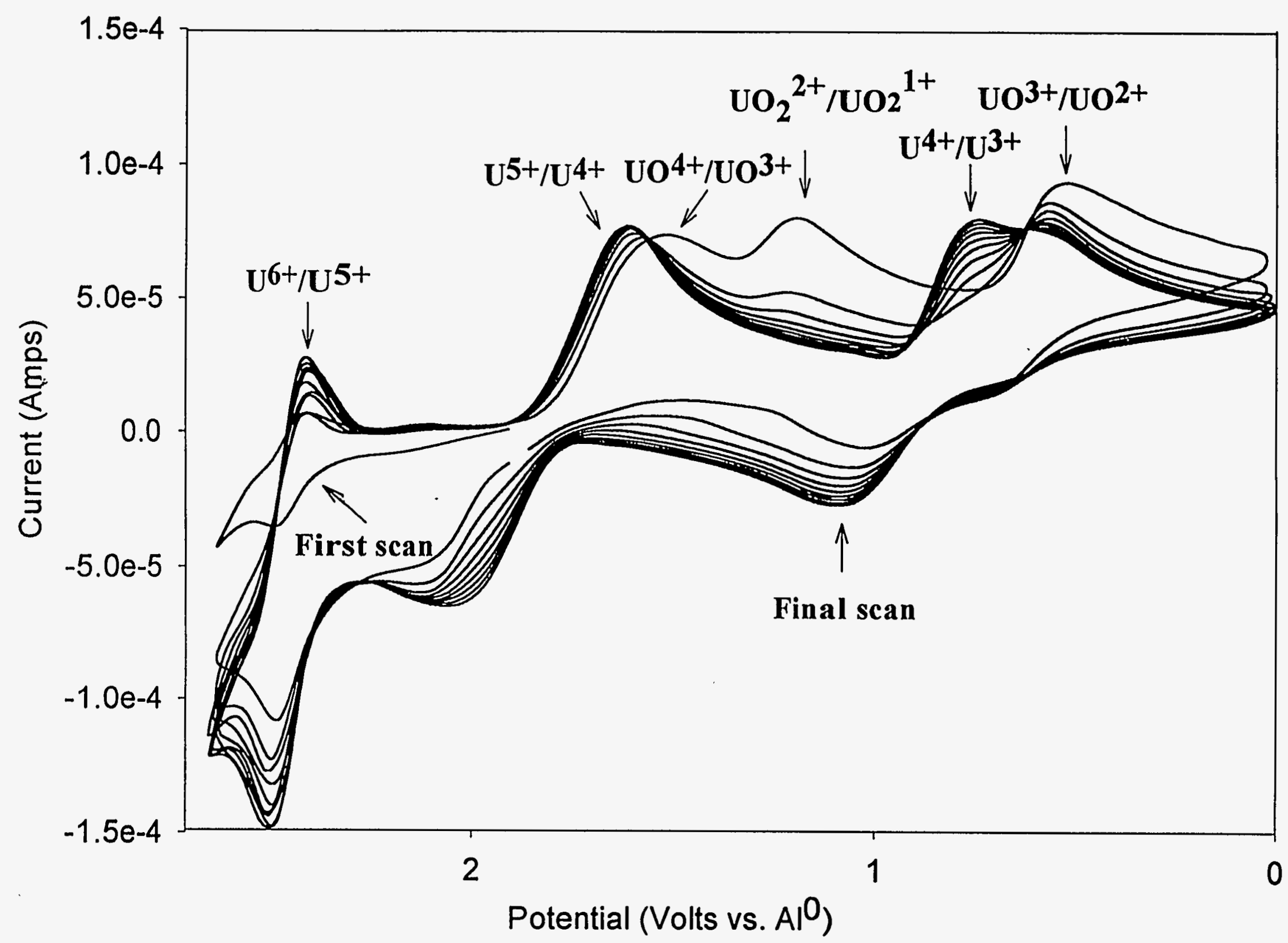

Figure 1. Cyclic voltammogram of $\mathrm{UO}_{2}{ }^{2+}$ in acidic $60: 40 \mathrm{AlCl}_{3}$ :ethyl-methyl-imidazolium chloride, repetitive scans at a scan rate of $100 \mathrm{mV} / \mathrm{s}$. 


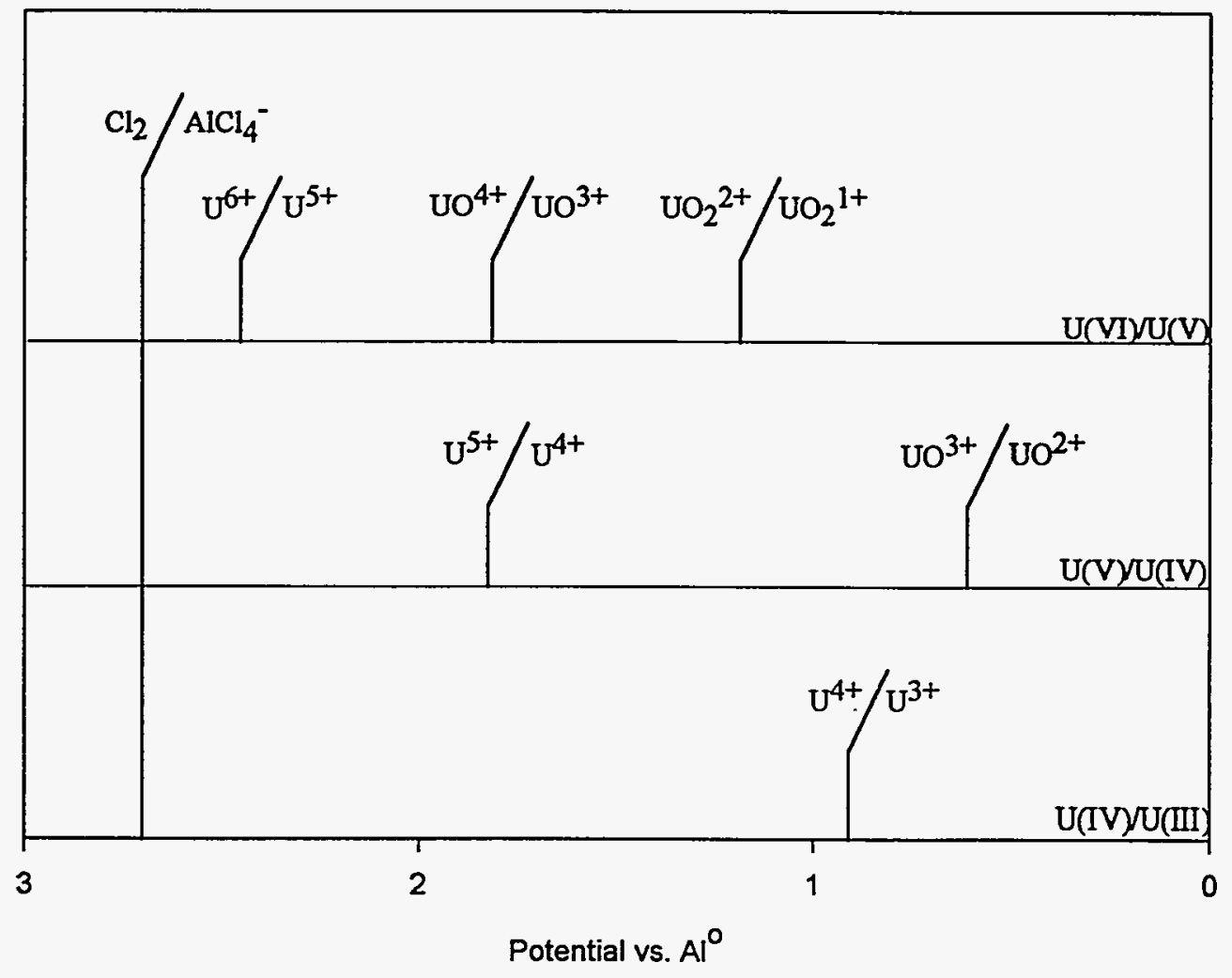

Figure 2. Redox potential assignments in acidic $\mathrm{AlCl}_{3}$ :ethyl-methyl-imidazolium chloride. 


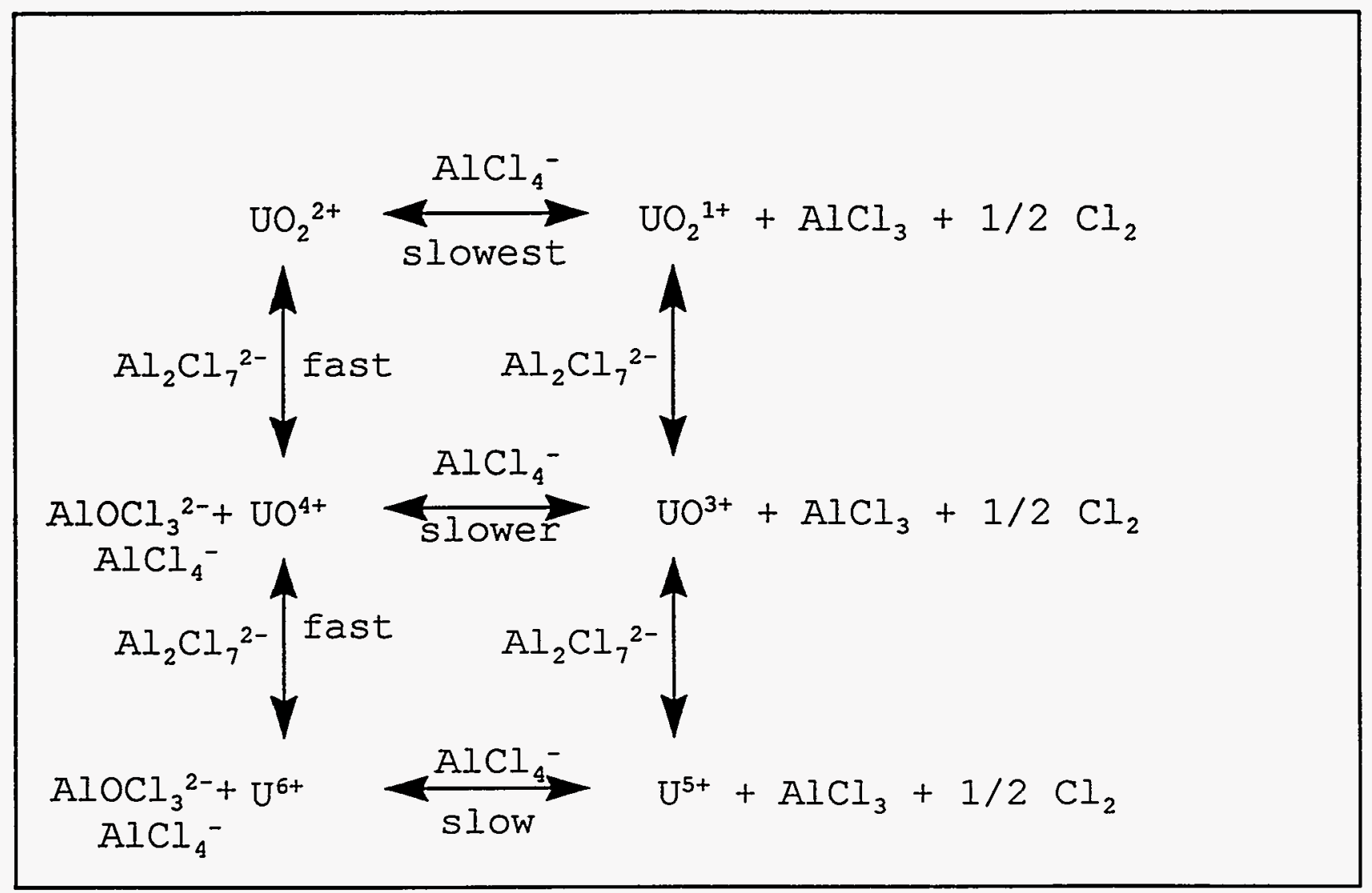

Figure 3. A proposed scheme for the mechanism of the net reaction of the reduction of $\mathrm{UO}_{2}^{2+}$ to $\mathrm{U}^{5+}$ in acidic $\mathrm{AlCl}_{3}$ :ethyl-methyl-imidazolium chloride. 